\title{
Effect of Nonsurgical Periodontal Treatment Combined With Diode Laser or Photodynamic Therapy on Chronic Periodontitis: A Randomized Controlled Split-Mouth Clinical Trial
}

\author{
Reza Birang ${ }^{1}$, Mohammad Shahaboui ${ }^{1}$, Sima Kiani ${ }^{1}{ }^{*}$, Elham Shadmehr ${ }^{2}$, Narges Naghsh ${ }^{1}$ \\ 'Department of Periodontology, Torabinejad Dental Research Center, Isfahan University of Medical Sciences, \\ Isfahan, Iran \\ ${ }^{2}$ Department of Endodontics, Torabinejad Dental Research Center, Isfahan University of Medical Sciences, \\ Isfahan, Iran
}

\author{
Correspondence to \\ Sima Kiani, DDS; Department \\ of Periodontology, Torabinejad \\ Dental Research Center, Isfahan \\ University of Medical Sciences, \\ Isfahan, Iran. \\ Tel: +98-3137925542; \\ Fax: +98-3137925580; \\ Email: \\ simakiani@dnt.mui.ac.ir
}

Published online 28 June 2015

\begin{abstract}
Introduction: The optimum removal of bacteria and their toxins from periodontal pockets is not always obtained by conventional mechanical debridement. Adjunctive therapies may improve tissue healing through detoxification and bactericidal effects. The purpose of the present study was to evaluate the impact of adjunctive laser therapy (LT) and photodynamic therapy (PDT) on patients with chronic periodontitis.

Methods: Twenty patients with at least three quadrants involved and each of them presenting pockets $4-8 \mathrm{~mm}$ deep were included in the study. Periodontal treatment comprising scaling and root planning (SRP) was accomplished for the whole mouth. Applying a split-mouth design, each quadrant was randomly treated with SRP alone (group A), SRP with LT (group B), and SRP with PDT (group C). The clinical indices were measured at baseline 6 weeks and 3 months after treatment. Microbiological samples were taken and evaluated at baseline and 3-month follow-up.

Results: All groups showed statistically significant improvements in terms of clinical attachment level (CAL) gain, periodontal pocket depth (PPD) reduction, papilla bleeding index and microbial count compared to baseline $(P<.05)$. The results showed more significant improvement in the 6-week evaluation in terms of $C A L$ in groups $B$ and $C$ than in group $A$ $(P<.05)$. Group $B$ also revealed a greater reduction in PPD than the other treatment modalities $(P<.05)$.

Conclusion: The obtained data suggested that adjunctive LT and PDT have significant shortterm benefits in the treatment of chronic periodontitis. Furthermore, LT showed minimal additional advantages compared to PDT.

Keywords: Periodontitis, chronic; Diode laser; Photodynamic therapy; Photosensitizing agent
\end{abstract}

\section{Introduction}

Periodontitis is a multifactorial inflammatory disease of periodontal tissues usually caused by extension of bacterial infection into subgingiva, ${ }^{1}$ which leads to the connective tissue destruction and alveolar bone loss. ${ }^{2,3}$ The essential objective of periodontal treatment is to decrease or eliminate the responsible periopathogens, ${ }^{4}$ by means of removing bacterial deposits from the tooth surface. ${ }^{5}$ Conventional mechanical debridement (ie, scaling and root planning [SRP]) is considered to be the gold standard for inflammatory periodontal disease treatment, ${ }^{6}$ which can cause an interim reduction in the levels of subgingival periopathogens. ${ }^{3}$ Despite clinical and microbiological im-
\end{abstract}

provements in most of cases, none of the current mechanical instruments alone are efficient in completely eliminating calculus and bacterial deposits from the periodontal pocket. ${ }^{7}$ Antimicrobial chemotherapy may further suppress the periodontal pathogens and increase the benefits obtained by the conventional mechanical treatment. ${ }^{8,9}$ Inefficiency of some antimicrobial drugs (ie, systemic antibiotics) is probably due to development of drug-resistant strains ${ }^{10,11}$ and the resulting side effects like possible allergic reactions, toxicity and gastrointestinal complications, which also have to be considered. ${ }^{12}$

Low level laser therapy (LT) is a potential adjunctive approach which was first shown to have wound healing

Please cite this article as follows: Birang R, Shahaboui M, Kiani S, Shadmehr E, Naghsh N. Effect of Nonsurgical periodontal treatment combined with diode laser or photodynamic therapy on chronic periodontitis: a randomized controlled split-mouth clinical trial. I Lasers Med Sci. 2015;6(3):112-119. doi:10.15171/jlms.2015.04. 
effects about four decades ago. ${ }^{13}$ Further investigations revealed some other beneficial effects of low level LT, including the promotion of cell proliferation, analgesic and anti-inflammatory effect ${ }^{14,15}$ and reduction of prostaglan$\operatorname{din} \mathrm{E}_{2}$ that may inhibit progression of gingivitis and periodontitis. ${ }^{16}$ Diode laser is applied to treat soft tissues due to its bactericidal and detoxification effects, but in treatment of chronic periodontitis, it may be useful as an adjunct to SRP because it is able to remove calculus and bacterial deposits. ${ }^{14,17}$ The effectiveness of LT in the treatment of periodontal diseases is still a controversial subject.

Photodynamic therapy (PDT) is a procedure which consists of exciting the photosensitizing agent to a higher energy state in presence of oxygen by means of laser light energy. ${ }^{18,19}$ Cytotoxic products such as singlet oxygen molecules with highly reactive energy are generated in this process, which may have bactericidal effect on periodontal microorganisms. ${ }^{18}$ The radius action of cytotoxic products cannot usually exceed more than $0.02 \mu \mathrm{m}$ off the radiation center. This characteristic may thus make PDT an appropriate noninvasive and localized treatment procedure. ${ }^{20}$ In addition, since its mechanism depends on chemically reactive molecules such as singlet oxygen and hydroxyl radicals, developing resistance to this treatment seems to be improbable. ${ }^{21}$ The advantage of PDT in reducing periopathogenic microorganisms in vitro is declared by experimental examinations. ${ }^{22,23}$ PDT is suggested as a treatment modality that can reduce the demand for flap surgery, and subsequently the chair time and risk of bacteremia. It can also be useful in difficult-to-access areas. ${ }^{24}$ However, numerous studies carried out in field of PDT, applying diode laser light and variant photosensitizers such as malachite green, ${ }^{25}$ toluidine blue, ${ }^{26}$ phenothiazine chloride ${ }^{27}$ and methylene blue, ${ }^{28}$ have reported conflicting clinical and microbial findings when comparing the effects of PDT adjunct to SRP with SRP alone.

So far, many studies have been conducted to evaluate the effect of $\mathrm{LT}^{29,30}$ or $\mathrm{PDT}^{27,31,32}$ in chronic periodontitis; however few studies have been designed to evaluate the efficacy of PDT eradication of laser light without applying photosensitizer agent. The present controlled clinical trial study was designed to clinically and microbiologically investigate the efficacy of adjunctive LT with low level diode laser and PDT, applying a novel photosensitizer (Emundo) and diode laser compared to conventional mechanical debridement in a group of patients with chronic periodontitis.

\section{Methods}

\section{Patients}

Twenty adult patients ( 13 females and 7 males; aged 18-72 years, mean age $37.2 \pm 8.6)$ presenting chronic periodontitis, who were referred to the department of periodontology, school of dentistry, Isfahan University of Medical Sciences for periodontal examination between September 2012 and February 2013, were selected. All patients were recruited according to the following criteria: (1) Age $\geq 18$, (2) Systemically healthy, (3) Remaining teeth $\geq 20$,
(4) Presence of 3 or more quadrants of mouth, each containing at least three sites with periodontal pocket depth (PPD) of 4-7 mm and clinical attachment level (CAL) of 2 $\mathrm{mm}$ or greater, and (5) Signed inform consent form.

The exclusion criteria consisted of: (1) Smoking or alcoholism, (2) Pregnancy or lactating, (3) Consuming antimicrobial drugs (ie, antibiotics) in the last 2 months, and (4) History of periodontal surgery in the last year.

The study protocol was approved by Ethics Committee of Isfahan University of Medical Sciences (IRCT ID: IRCT2015021021029N1). The study was conducted at Professor Torabinejad Dental Research Center joined to School of Dentistry, Isfahan University of Medical Sciences.

\section{Study Design}

The present study was designed as a split-mouth, double blind, randomized controlled clinical trial, and conducted for a follow-up period of three months. Using a randomization chart, the quadrants were assigned to the groups. In the first session, oral hygiene instruction included tooth brushing with modified Bass method and performing dental flossing. All patients practiced the oral hygiene procedure over a week to ensure adequate plaque control prior to baseline examination. In the next session full-mouth SRP were carried out for all patients applying ultrasonic instrument (Pizoscaler-Mectron ${ }^{\circledR}$, Italy). The procedure was performed under local anesthesia. The accuracy of SRP was checked one week later and completed if it was needed.

Different treatment approaches were assigned randomly to the three dental quadrants. In each quadrant, the three deepest pockets which met the inclusion criteria were selected for clinical and microbial evaluation. Hence, a total of 180 dental sites were included in the study (60 sites in each group). The sites in SRP group (group A) received only SRP. In laser group (group B) LT (with a wavelength of $810 \mathrm{~nm}$ [Fox ${ }^{\circledR}$, A.R.C. laser $\mathrm{GmbH}$, Germany]) was performed in addition to SRP. PDT group (group C) received PDT (with a wave length of $810 \mathrm{~nm}$ and applying Emundo ${ }^{\circledR}$ mixture [Emundo ${ }^{\circledR}$, A.R.C. laser $\mathrm{GmbH}$, Germany], as photosensitizer) as an adjunct to SRP. The treatment was performed for all quadrant sites but the examinations were carried out only in the selected dental pockets.

\section{Laser Therapy/Photodynamic Therapy}

The treatment was performed using a diode laser, $810 \mathrm{~nm}$ wavelength and $0.5 \mathrm{~W} / \mathrm{cm}^{2}$ power density together with photosensitizing agent. In group $\mathrm{C}$, the photosensitizer was injected into the periodontal pocket in an apical to coronal direction using a blunt needle straight application. The procedure was repeated for groups A and B with an obstructed needle but in the same pattern in order to keep the patients blind. Following that, the pockets in groups $\mathrm{B}$ and $\mathrm{C}$ were irradiated by the laser light according to the following steps:

Step 1: transgingival irradiation was performed by bleach- 


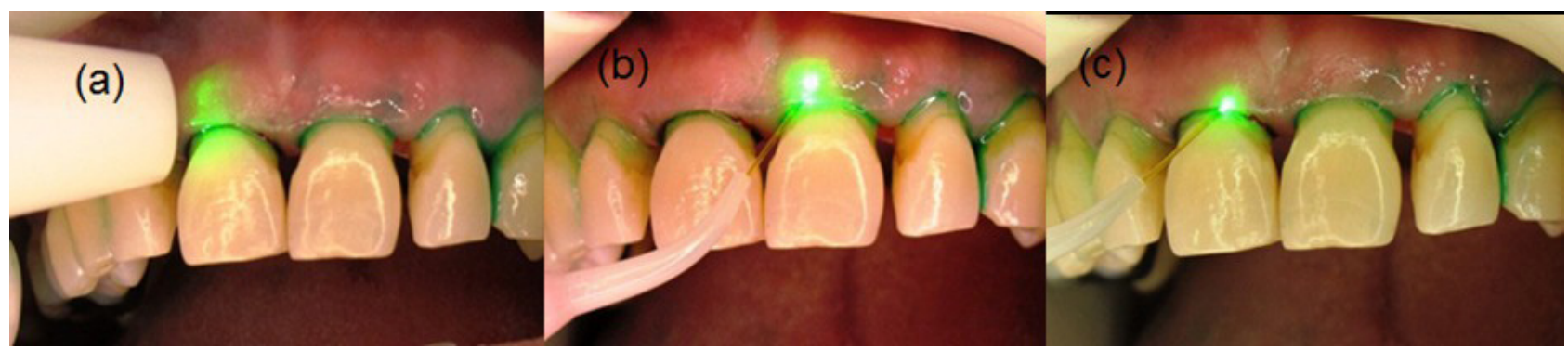

Figure 1. Photodynamic therapy (PDT) (a) Step 1: Transgingival irradiation by bleaching handpiece; (b) Step 2: Irradiation by a $300 \mu \mathrm{m}$ bare fiber in a circular pattern; (c) Step 3: Granulation tissue removal using a $300 \mu \mathrm{m}$ bare fiber.

ing headpiece ( $0.5 \mathrm{~W}, 10$ seconds). (Figure $1, \mathrm{a})$

Step 2: all pockets were irradiated by a $300 \mu \mathrm{m}$ bulb fiber in a circular pattern ( $0.5 \mathrm{~W}, 15$ seconds). (Figure $1, \mathrm{~b})$

Step 3: granulation tissue was removed from the infected pockets using a $300 \mu \mathrm{m}$ bare fiber in a circular pattern $(0.5$ W, 25 seconds). (Figure 1, c)

These steps were simulated in group A, but in an inactive laser mode; however, aiming laser light was active in order to keep the patients blind to the study design. The tip of laser fiber was discarded in the intervals between the patients' treatment. Finally, the pockets were rinsed with saline solution $(\mathrm{NaCl} 0.9 \%)$. The same therapeutic procedure was performed 2 weeks later. The periodontal treatment was entirely performed by the same experienced operator who was unaware of the main objectives of the study and was absent in the reevaluation sessions. During the LT and PDT procedures, the patients and the personnel were required to wear protective glasses. From the beginning to end of the study patients were visited every 2 weeks in order to inspect the occurrence of eventual side effects and to control plaque removal and root debridement if necessary.

\section{Clinical Measurements}

The following clinical parameters were measured at baseline (T0) - before performance of SRP - as well as 6 weeks (T1) and 3 months (T2) after periodontal treatment by a professional periodontal examiner who was weighed in terms of intra-examiner reproducibility.

PPD: applying a calibrated periodontal probe $\left(\mathrm{Hu}-\mathrm{Friedy}^{\circledR}\right.$, PQW7, USA) with point diameter of $0.5 \mathrm{~mm}$ and probing pressure of $0.75 \mathrm{~N}, \mathrm{PPD}$ was measured as the distance from the gingival margin to the bottom of the sulcus.

CAL: it was registered in a manner similar to PPD referenced to cemento-enamel junction.

Plaque Index (PI; Sillness \& Loe 1964) $)^{33}$

Papilla Bleeding Index (PBI; Saxer \& Muhlemann 1975) ${ }^{33}$ : using the same probing pressure, PBI was determined 30 seconds after probing.

\section{Microbiologic Assessment}

Microbiological samples were taken from the deepest pocket in each quadrant (one site per quadrant, in total 60 sites) at baseline and 3 months after treatment. The procedure was performed with a sterile paper point which was inserted in the bottom of the pocket for 20 seconds, after isolating the selected sites using cotton rolls (Figure 2). Subsequently, each sample was pooled in a sterile vial and sent to the laboratory for genome analysis (pooled sample). The microbiological sample analysis was performed with real time polymerase chain reaction method (RT-PCR) using the commercially available kit (Kiagen ${ }^{\circledR}$, USA) to evaluate the amount of Actinobacillus actinomycetemcomitans, Porphyromonas gingivalis and Treponema denticola.

\section{Statistical Analysis}

The means and standard deviations were computed for all clinical and microbial variables of each treatment group. The data were processed using statistical software (SPSS 16.O, IBM, Chicago, IL). Kolmogorov-Smirnov test was used to confirm the normal distribution of the data. Kruskal-Wallis test was opted for multiple comparisons of the nonparametric data (PPD reduction, CAL gain, PI and PBI) between groups. In addition, Mann-Whitney test was applied to compare the groups. Friedman and complementary Wilcoxon signed-ranks test were applied to determine the differences in the means of clinical parameters for the baseline, 6 weeks and 3 months. Oneway analysis of variance (ANOVA) was used in order to compare the microbial variables between the groups after

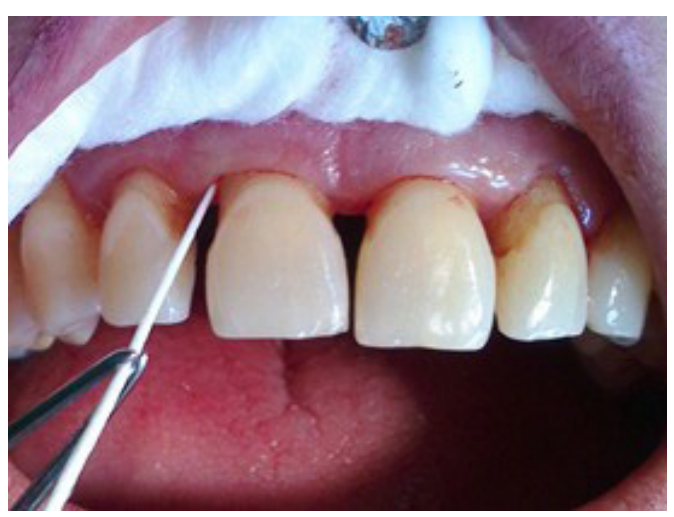

Figure 2. Microbiological samples were taken from the deepest pocket in each quadrant. The procedure was performed with a sterile paper point which was inserted in the bottom of the pocket for 20 seconds, after isolating the selected sites using cotton rolls. 
confirming the normality of data distribution. Paired $t$ test was used to determine the significance of the difference between baseline and 3 months within each group. $P<.05$ was considered significant.

\section{Results}

A total of 180 single-rooted teeth from 20 patients were included in the current study. All patients completed the 3 -month course of the study. Healing occurred in all cases with no adverse effects such as pain, burning sensation or any other uncomfortable feeling.

The information about clinical parameters (PPD, CAL, PI and PBI) at baseline, 6 weeks and 3 months after the treatment, the amount of changes per group $(\triangle \mathrm{PPD}$, $\triangle \mathrm{CAL}, \triangle \mathrm{PBI}, \Delta \mathrm{PI}$ ) from baseline to 6 weeks and 3 months after the treatment and the relevant statistical analysis are shown in Table 1. No significant difference was observed among groups for any of the clinical parameters at baseline, whereas significant clinical improvements were observed between groups at 6 weeks and 3 months after treatment in terms of PPD reduction, CAL gain and PBI $(P<.001)$. PI values showed no statistically significant difference from baseline to 6-week and 3-month evaluations in the groups, except in 6-weeks assessment of group B compared to baseline $(P<.05)$.

Group B revealed a greater PPD reduction compared to other groups $(P<.05)$. Furthermore, groups $\mathrm{B}$ and $\mathrm{C}$ indicated a higher CAL gain at 6 -week evaluation than group A $(P<.05)$. However, there were no statistically significant differences between groups regarding this parameter 3 months after treatment. The comparison between groups showed no significant difference in terms of $\triangle \mathrm{PBI}$ and $\Delta$ PI (Table 1).

Bacterial count (mean \pm SD) for all evaluated bacterial species (A.a, P.g and T.d) at baseline and 3-month evaluations is presented in Table 2. All bacterial species de-

Table 1. Values of Mean \pm SD of Clinical Parameters for Applied Therapeutic Procedures

\begin{tabular}{|c|c|c|c|c|c|}
\hline Clinical Parameter & Evaluation Point & Group A SRP & Group B LT & Group C PDT & $P$ Value \\
\hline \multicolumn{6}{|l|}{ PPD (mm) } \\
\hline & Base line & $5.14 \pm 1.24$ & $5.25 \pm 1.39$ & $5.11 \pm 1.13$ & .03 \\
\hline & 6 weeks & $4.48 \pm 1.45$ & $3.93 \pm 1.42$ & $4.33 \pm 1.56$ & \\
\hline & $P$ value & 0.000 & 0.000 & 0.000 & \\
\hline & $\Delta 0-6 \mathrm{w}$ & $0.65 \pm 1.07$ & $1.31 \pm 1.70$ & $0.78 \pm 1.41$ & \\
\hline & Base line & $5.14 \pm 1.24$ & $5.25 \pm 1.39$ & $5.11 \pm 1.13$ & .027 \\
\hline & 3 months & $4.03 \pm 1.38$ & $3.63 \pm 1.40$ & $4.18 \pm 1.54$ & \\
\hline & $P$ value & 0.000 & 0.000 & 0.000 & \\
\hline & $\Delta 0-3 \mathrm{~m}$ & $0.92 \pm 1.24$ & $1.59 \pm 1.77$ & $0.89 \pm 1.34$ & \\
\hline \multicolumn{6}{|l|}{ CAL (mm) } \\
\hline & Base line & $4.94 \pm 1.67$ & $4.97 \pm 1.69$ & $5.06 \pm 1.54$ & .018 \\
\hline & 6 weeks & $4.46 \pm 1.55$ & $4.00 \pm 1.58$ & $4.10 \pm 1.78$ & \\
\hline & $P$ value & 0.000 & 0.000 & 0.000 & \\
\hline & $\Delta 0-6 \mathrm{w}$ & $0.48 \pm 1.02$ & $0.96 \pm 1.5$ & $0.95 \pm 1.30$ & \\
\hline & Base line & $4.94 \pm 1.67$ & $4.97 \pm 1.69$ & $5.06 \pm 1.54$ & .50 \\
\hline & 3 months & $3.90 \pm 1.68$ & $3.80 \pm 1.73$ & $4.10 \pm 1.77$ & \\
\hline & $P$ value & 0.000 & 0.000 & 0.000 & \\
\hline & $\Delta 0-3 \mathrm{~m}$ & $0.83 \pm 1.50$ & $1.17 \pm 1.64$ & $0.92 \pm 1.30$ & \\
\hline \multicolumn{6}{|l|}{ PI mean score } \\
\hline & Base line & $0.89 \pm 0.87$ & $1 \pm 0.98$ & $0.97 \pm 0.87$ & .26 \\
\hline & 6 weeks & $0.79 \pm 0.77$ & $0.70 \pm 0.71$ & $0.75 \pm 0.84$ & \\
\hline & $P$ value & 0.27 & $0.002^{*}$ & 0.060 & \\
\hline & $\Delta 0-6 \mathrm{w}$ & $0.10 \pm 0.90$ & $0.29 \pm 0.83$ & $0.22 \pm 0.99$ & \\
\hline & Base line & $0.89 \pm 0.87$ & $1 \pm 0.98$ & $0.97 \pm 0.87$ & .60 \\
\hline & 3 months & $0.71 \pm 0.92$ & $0.90 \pm 0.89$ & $0.77 \pm 0.88$ & \\
\hline & $P$ value & 0.20 & 0.30 & 0.116 & \\
\hline & $\Delta 0-3 \mathrm{~m}$ & $0.13 \pm 1.05$ & $0.11 \pm 0.15$ & $0.21 \pm 1.14$ & \\
\hline \multicolumn{6}{|l|}{ PBI mean score } \\
\hline & Base line & $2.5 \pm 1.05$ & $2.67 \pm 0.93$ & $2.5 \pm 0.82$ & .10 \\
\hline & 6 weeks & $2.28 \pm 0.89$ & $2.03 \pm 0.87$ & $2.04 \pm 0.81$ & \\
\hline & $P$ value & 0.23 & 0.000 & 0.000 & \\
\hline & $\Delta 0-6 \mathrm{w}$ & $0.29 \pm 1.19$ & $0.63 \pm 1.15$ & $0.50 \pm 0.95$ & \\
\hline & Base line & $2.5 \pm 1.05$ & $2.67 \pm 0.93$ & $2.5 \pm 0.82$ & .12 \\
\hline & 3 months & $1.92 \pm 0.82$ & $1.73 \pm 0.83$ & $1.92 \pm 0.96$ & \\
\hline & P value & 0.002 & 0.000 & 0.000 & \\
\hline & $\Delta 0-3 \mathrm{~m}$ & $0.1 \pm 1.23$ & $0.94 \pm 1.23$ & $0.62 \pm 1.27$ & \\
\hline
\end{tabular}

Abbreviations: SRP, scaling and root planning; LT, laser therapy; PDT, photodynamic therapy; PPD, periodontal pocket depth; CAL, clinical attachment level; PI, plaque index; PBI, papilla bleeding index. 
Table 2. Values of Mean \pm SD for Bacterial Loads at Baseline and After 3 months in Each Group

\begin{tabular}{|c|c|c|c|c|c|}
\hline Bacterial Species & Evaluation Point & Group A & Group B & Group C & $P$ Value \\
\hline \multicolumn{6}{|c|}{ Aggregatibacter actinomycetemcomitans } \\
\hline & Base line & $2233 \pm 1090$ & $2520 \pm 671$ & $2912 \pm 2103$ & \multirow[t]{4}{*}{.689} \\
\hline & 3 months & $555 \pm 245$ & $8200 \pm 573$ & $662 \pm 358$ & \\
\hline & $P$ value & 0.004 & 0.000 & 0.025 & \\
\hline & $\Delta 0-3 \mathrm{~m}$ & $1677 \pm 1258$ & $1700 \pm 970$ & $2250 \pm 2236$ & \\
\hline \multicolumn{6}{|c|}{ Porphyromonas gingivalis } \\
\hline & Base line & $15.11 \pm 826$ & $17.6 \pm 689$ & $1487 \pm 701$ & \multirow[t]{4}{*}{.727} \\
\hline & 3 months & $4.55 \pm 343$ & $4.9 \pm 280$ & $500 \pm 239$ & \\
\hline & $P$ value & 0.002 & 0.001 & 0.010 & \\
\hline & $\Delta 0-3 \mathrm{~m}$ & $10.55 \pm 709$ & $12.7 \pm 842$ & $987 \pm 802$ & \\
\hline \multicolumn{6}{|c|}{ Treponema denticola } \\
\hline & Base line & $1722 \pm 591$ & $1720 \pm 841$ & $1725 \pm 777$ & \multirow[t]{4}{*}{.739} \\
\hline & 3 months & $355 \pm 287$ & $690 \pm 615$ & $650 \pm 396$ & \\
\hline & $P$ value & 0.000 & 0.026 & 0.016 & \\
\hline & $\Delta 0-3 \mathrm{~m}$ & $1366 \pm 691$ & $1030 \pm 1226$ & $1074 \pm 966$ & \\
\hline
\end{tabular}

creased significantly from baseline to the 3-month evaluations $(P<.05)$ with no significant difference between the three treatment modalities (Table 2).

\section{Discussion}

The results of the present study revealed that adjunctive LT or PDT can improve the short-term clinical results of conventional periodontal treatment in chronic periodontitis. Today, it is obvious that conventional SRP are prerequisite for a constant periodontal treatment success. ${ }^{34} \mathrm{How}^{-}$ ever, the results of conventional mechanical debridement can be improved by development of novel therapeutic approaches. Nowadays, adjuvant low-level laser therapies alone or combined with dyes as photosensitizer are available in addition to the traditional treatment using SRP. The present study was designed in order to evaluate the effect of conventional periodontal debridement combined with LT or PDT on periodontal clinical and microbial results in cases with chronic periodontitis.

All treatment modalities in this study caused statistically significant improvements in the evaluated clinical and microbiological parameters at 6-week and 3-month courses compared to baseline. There was no statistically significant difference regarding PI and PBI between groups.

A greater gain of attachment was observed in groups $B$ and $\mathrm{C}$ compared to group $\mathrm{A}$ at 6-week follow-up examination. The difference between groups $\mathrm{B}$ and $\mathrm{C}$ was not statistically significant. However, there was no statistically significant difference regarding CAL gain between the groups 3 months after treatment in this study. Similarly, some studies have shown no significant difference in attachment gain between cases treated with SRP combined with diode laser ${ }^{35,36}$ or PDT $\mathrm{PD}^{27,37}$ and those treated only with SRP. These finding are not in agreement with those of some recent randomized clinical trials, which showed that treatment with low-level laser irradiation ${ }^{38}$ and PDT $^{32,39}$ as an adjunct to conventional SRP have more efficacy in attachment gain than SRP alone. The most probable rea- son for lack of difference between test groups and control group at the 3-month evaluation is discontinuity of LT and PDT despite the manufacturer's instruction.

The results of the present study showed that low-level diode LT associated with conventional SRP was more effective in reducing PPD than the ones achieved by PDT together with SRP or SRP alone. Similar findings were shown in a very recent randomized clinical trial ${ }^{40} \mathrm{com}-$ paring the efficacy of potassium titanyl phosphate (KTP) laser and PDT in chronic periodontitis treatment. Contradictory results, however, were reported by a randomized clinical trial ${ }^{41}$ investigating the efficacy of PDT, diode laser and deep scaling in the treatment of residual pockets and indicated that fewer infected pockets may remain after PDT or deep scaling than diode laser application after 6 months. A recent systematic meta-analysis, ${ }^{42}$ comparing the efficacy of adjunctive PDT to conventional mechanical debridement, showed that PDT combined with SRP can improve the efficacy of treatment in term of CAL gain and PPD reduction. The obvious discrepancy between the studies might be due to different types of laser application, wavelength used in the study and the type of photosensitizer.

PI was not significantly changed in the groups from baseline to 3 months follow-up. The only significant change in PI was observed in 6 weeks follow up in the laser group; nevertheless, there was no significant difference between the groups regarding this variable. Given that oral hygiene was instructed equally to all participants, practiced enough before starting the study and well maintained during the whole experimentation period, these findings are justifiable. Furthermore, there is no strong evidence to support the difference between nonsurgical or surgical therapies regarding post-treatment plaque accumulation. It is also documented that the severity of gingivitis resolution is not affected by the treatment modalities. ${ }^{43}$ Similarly, there is no evidence strongly confirming that LT or PDT can prevent formation of biofilm once the root sur- 
face has been irradiated.

PBI improved equally in all groups from baseline to the follow-up assessments 6 weeks and 3 months after treatment. Reduction of PBI in the present study confirms the findings of Lang et $\mathrm{al}^{44}$ indicating that decrease in bleeding on probing score is associated with reduction in periodontal inflammation. Lang et $\mathrm{al}^{44}$ indicated that bleeding on probing is a prognostic factor for periodontal disease progress. Our findings are not in line with a number of previous clinical investigations which presented significantly better results in PBI or bleeding on probing index for SRP combined with adjunctive PDT ${ }^{45}$ or adjuvant $\mathrm{LT}^{35}$ than for SRP alone.

In the present study, the mean microbial levels diminished significantly in all experimental groups without a significant difference between them. These results are in agreement with those obtained by Christodoulides et al. ${ }^{27}$ Similar results were also obtained by Cappuyns et $\mathrm{al}^{41}$ showing the same frequency of Porphyromonas gingivalis (Pg), Tannerella forsythensis (Tf), Treponema denticola (Td), in groups treated with adjunctive LT, PDT or SRP alone 2 and 6 months after treatment. However, Cappuyns et $\mathrm{al}^{41}$ emphasized the stronger suppression of micro-organisms in PDT and SRP groups than in laser group after 14 days of treatment. Conversely, an in vitro study ${ }^{46}$ showed that use of PDT on oral bacteria effectively eliminated Actinobacillus actinomycetemcomitans (Aa), Porphyromonas gingivalis (Pg), and Fusobacterium nucleatum (Fn). However, a direct comparison of in vitro studies with those of the human studies is complicated. So, they need to be discussed with precaution. Moreover, the literature ${ }^{47}$ has indicated that the bactericidal effect of lasers is the main reason for their increasing application as an additional therapy to conventional periodontal treatment.

In the present study, the reduced frequency of PDT or laser application than defined by the manufacturer is a possible explanation for some similar results between the groups. The manufacturer suggested repeated PDT performance within 3 months (1 day, 2 weeks, 6 weeks, and 3 months); however in order to inhibit additional confounding factors (ie, frequency of considered treatment) only 2 episodes of PDT and LT were applied. There is not any standard procedure considering energy and mode of irradiation, time taken for microbial reduction in the pocket and the power needed, which provide the proper analysis of the results. In this study the clinical parameters suggested by manufacturer (A.R.C. laser $\mathrm{GmbH}$, Germany) were followed.

Another important point that should be kept in mind while interpreting the clinical and microbial findings obtained by PDT is the effect of the photosensitizer itself.

Since PDT is more time consuming and costly than LT, further studies are needed in order to evaluate the efficacy of applying a photosensitizer in combination with light application compared to LT alone.

\section{Conclusion}

Within its limits, the present study demonstrated that ad- junctive LT or PDT resulted in more improvement in term of CAL gain compared to SRP alone, only in short-term evaluation. Regarding PPD reduction, adjunctive LT was more efficient than adjunctive PDT or SRP alone.

\section{Conflict of Interest}

The authors have no conflict of interest to declare.

\section{Reference}

1. Andersen R, Loebel N, Hammond D, Wilson M. Treatment of periodontal disease by photodisinfection compared to scaling and root planing. J Clin Dent. 2007;18(2):34-38.

2. Renvert S, Dahlen G, Wikstrom M. Treatment of periodontal disease based on microbiological diagnosis. Relation between microbiological and clinical parameters during 5 years. J Periodontol. 1996;67(6):562-571. doi:10.1902/jop.1996.67.6.562.

3. Sbordone L, Ramaglia L, Gulletta E, Iacono V. Recolonization of the subgingival microflora after scaling and root planing in human periodontitis. J Periodontol. 1990;61(9):579-584. doi:10.1902/ jop.1990.61.9.579.

4. Teles RP, Haffajee AD, Socransky SS. Microbiological goals of periodontal therapy. Periodontol. 2000. 2006;42:180-218.

5. Cobb CM. Non-surgical pocket therapy: mechanical. Ann Periodontol. 1996;1(1):443-490. doi:10.1902/ annals.1996.1.1.443.

6. Soukos NS, Goodson JM. Photodynamic therapy in the control of oral biofilms. Periodontol 2000. 2011;55(1):143-166. doi:10.1111/j.16000757.2010.00346.x.

7. Adriaens PA, Adriaens LM. Effects of nonsurgical periodontal therapy on hard and soft tissues. Periodontol 2000. 2004;36:121-145. doi:10.1111/ j.1600-0757.2004.03676.x.

8. Chaves ES, Jeffcoat MK, Ryerson CC, Snyder B. Persistent bacterial colonization of Porphyromonas gingivalis, Prevotella intermedia, and Actinobacillus actinomycetemcomitans in periodontitis and its association with alveolar bone loss after 6 months of therapy. J Clin Periodontol. 2000;27(12):897-903.

9. Stabholz A, Nicholas AA, Zimmerman GJ, Wikesjo UM. Clinical and antimicrobial effects of a single episode of subgingival irrigation with tetracycline $\mathrm{HCl}$ or chlorhexidine in deep periodontal pockets. $J$ Clin Periodontol. 1998;25(10):794-800.

10. Feres M, Haffajee AD, Goncalves C, et al. Systemic doxycycline administration in the treatment of periodontal infections (II). Effect on antibiotic resistance of subgingival species. J Clin Periodontol. 1999;26(12):784-792.

11. Olsvik B, Tenover FC. Tetracycline resistance in periodontal pathogens. Clin Infect Dis. 1993;16(suppl 4):S310-S313.

12. Moritz A, Gutknecht N, Schoop U, Goharkhay K, Doertbudak O, Sperr W. Irradiation of infected 
root canals with a diode laser in vivo: results of microbiological examinations. Lasers Surg Med. 1997;21(3):221-226.

13. Mester E, Spiry T, Szende B, Tota JG. Effect of laser rays on wound healing. Am J Surg. 1971;122(4):532535.

14. Moritz A, Schoop U, Goharkhay K, et al. Treatment of periodontal pockets with a diode laser. Lasers Surg Med. 1998;22(5):302-311.

15. Pfitzner A, Sigusch BW, Albrecht V, Glockmann E. Killing of periodontopathogenic bacteria by photodynamic therapy. J Periodontol. 2004;75(10):1343-1349.

16. Hughes F. Color atlas of dental medicine: Periodontology. Br Dent J. 2005;198(10):655-655.

17. Harris DM, Yessik M. Therapeutic ratio quantifies laser antisepsis: ablation of Porphyromonas gingivalis with dental lasers. Lasers Surg Med. 2004;35(3):206213. doi:10.1002/1sm.20086

18. Konopka K, Goslinski T. Photodynamic therapy in dentistry. J Dent Res. 2007;86(8):694-707.

19. Von Tappeiner H, Jodlbauer A. On the effect of photodynamic (fluorescent) substances on protozoa and enzymes (in German). Deutsch Arch Klin Medizin. 1904(39):427-487.

20. Moan J, Berg K. The photodegradation of porphyrins in cells can be used to estimate the lifetime of singlet oxygen. Photochem Photobiol. 1991;53(4):549-553.

21. Ehrenberg B, Gross E, Nitzan Y, Malik Z. Electric depolarization of photosensitized cells: lipid vs. protein alterations. Biochim Biophys Acta. 1993;1151(2):257-264.

22. Soukos NS, Mulholland SE, Socransky SS, Doukas AG. Photodestruction of human dental plaque bacteria: enhancement of the photodynamic effect by photomechanical waves in an oral biofilm model. Lasers Surg Med. 2003;33(3):161-168. doi:10.1002/ lsm.10208.

23. Nastri L, Donnarumma G, Porzio C, et al. Effects of toluidine blue-mediated photodynamic therapy on periopathogens and periodontal biofilm: in vitro evaluation. Int J Immunopathol Pharmacol. 2010;23(4):1125-1132.

24. Zanin ICJ, Brugnera AJ. Terapia fotodinâmica no tratamento da doença periodontal. Perionews. 2007;1:79-85.

25. Prates RA, Yamada AM, Jr., Suzuki LC, et al. Bactericidal effect of malachite green and red laser on Actinobacillus actinomycetemcomitans. J Photochem Photobiol B. 2007;86(1):70-76. doi:10.1016/j. jphotobiol.2006.07.010.

26. Qin Y, Luan X, Bi L, et al. Toluidine blue-mediated photoinactivation of periodontal pathogens from supragingival plaques. Lasers Med Sci. 2008;23(1):4954. doi:10.1007/s10103-007-0454-X.

27. Christodoulides N, Nikolidakis D, Chondros P, et al. Photodynamic therapy as an adjunct to non-surgical periodontal treatment: a randomized, controlled clinical trial. J Periodontol. 2008;79(9):1638-1644. doi:10.1902/jop.2008.070652

28. Giannelli M, Formigli L, Lorenzini L, Bani D. Combined photoablative and photodynamic diode laser therapy as an adjunct to non-surgical periodontal treatment: a randomized split-mouth clinical trial. J Clin Periodontol. 2012;39(10):962-970. doi:10.1111/j.1600-051X.2012.01925.x.

29. Caruso U, Nastri L, Piccolomini R, d'Ercole S, Mazza C, Guida L. Use of diode laser $980 \mathrm{~nm}$ as adjunctive therapy in the treatment of chronic periodontitis. A randomized controlled clinical trial. New Microbiol. 2008;31(4):513-518.

30. De Micheli G, de Andrade AK, Alves VT, Seto M, Pannuti CM, Cai S. Efficacy of high intensity diode laser as an adjunct to non-surgical periodontal treatment: a randomized controlled trial. Lasers Med Sci. 2011;26(1):43-48.

31. Romanos GE, Brink B. Photodynamic therapy in periodontal therapy: microbiological observations from a private practice. Gen Dent. 2010;58(2):e68-73.

32. Braun A,Dehn C, KrauseF, Jepsen S. Short-term clinical effects of adjunctive antimicrobial photodynamic therapy in periodontal treatment: a randomized clinical trial. J Clin Periodontol. 2008;35(10):877-884. doi:10.1111/j.1600-051X.2008.01303.x.

33. Wolf HF, Rateitschak KH. Periodontology. Vol 1. Thieme; 2005.

34. Greenstein G. Periodontal response to mechanical non-surgical therapy: a review. J Periodontol. 1992;63(2):118-130. doi:10.1902/jop.1992.63.2.118.

35. Borrajo JL, Varela LG, Castro GL, Rodriguez-Nunez I, Torreira MG. Diode laser $(980 \mathrm{~nm})$ as adjunct to scaling and root planing. Photomed Laser Surg. 2004;22(6):509-512. doi:10.1089/pho.2004.22.509.

36. Euzebio Alves VT, de Andrade AK, Toaliar JM, et al. Clinical and microbiological evaluation of high intensity diode laser adjutant to non-surgical periodontal treatment: a 6-month clinical trial. Clin Oral Investig. 2013;17(1):87-95. doi:10.1007/s00784012-0703-7.

37. Balata ML, Andrade LP, Santos DB, et al. Photodynamic therapy associated with full-mouth ultrasonic debridement in the treatment of severe chronic periodontitis: a randomized-controlled clinical trial. J Appl Oral Sci. 2013;21(2):208-214. doi:10.1590/1678-7757201302366.

38. Birang R, Yaghini J, Adibrad M, Kiany S, Mohammadi Z, Birang E. The Effects of Diode Laser (980 nm Wavelength) and Chlorhexidin Gel in the Treatment of Chronic Periodontitis. J Lasers Med Sci. 2011;2(4):131-138.

39. Lulic M, Leiggener Gorog I, Salvi GE, Ramseier CA, Mattheos N, Lang NP. One-year outcomes of repeated adjunctive photodynamic therapy during periodontal maintenance: a proof-ofprinciple randomized-controlled clinical trial. J Clin Periodontol. 2009;36(8):661-666. doi:10.1111/j.1600- 
051X.2009.01432.x.

40. Dilsiz A, Canakci V, Aydin T. Clinical effects of potassium-titanyl-phosphate laser and photodynamic therapy on outcomes of treatment of chronic periodontitis: a randomized controlled clinical trial. J Periodontol. 2013;84(3):278-286. doi:10.1902/ jop.2012.120096.

41. Cappuyns I, Cionca N, Wick P, Giannopoulou C, Mombelli A. Treatment of residual pockets with photodynamic therapy, diode laser, or deep scaling. A randomized, split-mouth controlled clinical trial. Lasers Med Sci. 2012;27(5):979-986. doi:10.1007/ s10103-011-1027-6.

42. Sgolastra F, Petrucci A, Severino M, Graziani F, Gatto R, Monaco A. Adjunctive photodynamic therapy to non-surgical treatment of chronic periodontitis: a systematic review and meta-analysis. J Clin Periodontol. 2013;40(5):514-526. doi:10.1111/ jcpe.12094.

43. Wennstrom JL, Heijl L, Lindhe J. Periodontal Surgery:
Access Therapy. Bangalore, Karnataka: Blackwell Munksgaard; 2008: 783-822. Clinical Periodontology and Implant dentistry; vol 1.

44. Lang NP, Joss A, Orsanic T, Gusberti FA, Siegrist BE. Bleeding on probing. A predictor for the progression of periodontal disease? J Clin Periodontol. 1986;13(6):590-596.

45. Polansky R, Haas M, Heschl A, Wimmer G. Clinical effectiveness of photodynamic therapy in the treatment of periodontitis. J Clin Periodontol. 2009;36(7):575-580.

46. Dobson J, Wilson M. Sensitization of oral bacteria in biofilms to killing by light from a low-power laser. Arch Oral Biol. 1992;37(11):883-887.

47. Schwarz F, Sculean A, Berakdar M, Georg T, Reich E, Becker J. Periodontal treatment with an Er:YAG laser or scaling and root planing. A 2-year follow-up split-mouth study. J Periodontol. 2003;74(5):590-596. doi:10.1902/jop.2003.74.5.590. 